\title{
The Use of ITCs on Counselors to Enhance Professionalism: a Preliminary Study
}

\author{
Carolina L. Radjah, Adi Atmoko, Irene Maya Simon \\ Guidance and Counseling \\ Universitas Negeri Malang \\ Malang, Indonesia \\ carolina.ligya.fip@um.ac.id
}

\begin{abstract}
The purpose of this study wass to examine the usage of ITCs by a counselor. This study conducted a survey method to gather the data from five cities in Indonesia, among of them are Malang, Kupang, Ponorogo, Manado, and Palangkaraya. The participants of this study were the counselors that consisted of 156 respondents. The survey results adhered some key points related to media, facilities, activities, duration in using technology and information, and program or application used in cyber counseling. The results of this study indicated that counselor's usage of ITC varies although only half of the participants using cyber counseling for their counseling session.
\end{abstract}

Keywords: information and technology, counselor, professionalism

\section{INTRODUCTION}

The quality of competence standards of counselors becomes a major concern in pre-service education and education in service [1]. As a whole, the counselor's competence refers to the mastery of concepts, full and total comprehension, a manifestation of values, a personal appearance that is helpful, and professional performance that is accountable. The counselor's competence must be built from the philosophical foundations of human nature and life as a creature of God, personal, and citizen in the context of Indonesian culture [2].

The position of counselor profession is between education and psychology [3]. According to this opinion, a counselor is not a teacher but he/she has experience and ability as a teacher; the counselor is also not a psychologist. The uniqueness of counselor profession, which distinguishes it from the other professional helpers are the services provided by the counselors which are based on a developmental view. In the developmental view of, an individual faces developmental tasks, challenges, or problems throughout his/her life, and not everyone can accomplish them well. The inability of individuals to complete the developmental tasks is not understood as an abnormality but it is understood as a disparity. Consequently, the counselor must actively identify the service needs and simultaneously develop programs to meet the needs of the service.

In general, Indonesian Counselor Competence Standards have been mandated to all counselors to master the computer technology and the internet for the benefit of providing guidance and counseling services at school. An identification of guidance and counseling services that can be done with computer technology and internet has also been done.

The task of the counselor is to develop the potential and to make the counselees autonomous in decision-making and choice to create a productive and prosperous life, and care for the welfare of the counselees [4]. For that intention, the counselor is required to always think reflectively, meaning that the counselor always does self-evaluation of all his/her performance and is ready to make improvements so that he/she can bring an effective performance. Counseling is worth to be expressed as expert services because its application requires a decision that is not in the form of prescriptions which is simply delivered on counselees during the implementation of counseling [5]-[7]. Professional counselors are required to always question why, how, when their professional action is carried out, not just simply understand what is happening during the counseling process takes place.

According to Joni [4], the problems in the field shows that counseling competence has not yet performed better in the preservice education and education in service. Practical work activity is still so far from sufficiency. This is due to the feedback process in the lab work has not yet reached the development of metacognition. The counseling services conducted by counselors at schools are still very rigid (mechanistic), when the counselor should do his/her job based on the needs of the individuals served, not just simply perform the tasks based on the technical guidance of counseling.

Counseling services activities at school will effectively facilitate the counselee when the activities are carried out by a professional counselor. To conduct the professional activities, a counselor should always be relevant to the changes and developments of science and society, for that, it requires continuous professional development activities known as continuing professional development (CPD).

Along with the development of technology and information, online media can facilitate the counselor, the community gets information, conveys ideas, thoughts and ideas for the advancement of organizations of counselor's profession. In improving its services, counselors start using media that can support the needs of the counselee. Not all counselees have 
quite a lot of time to perform the activities or counseling process so that counseling service-based Information Technology and Guidance service is expected to facilitate the counselor.

Online counseling is a therapy which is not categorized as a strict therapy but it may also contain consultation for the improvement of mental and behavioral health through phone, e-mail, synchronous chat, and video conferencing [8]. According to [9], the familiarity with technology and the calm in facing technical problems are the keys to provide a better experience in online counseling. Furthermore, there are some basic considerations of online counseling: (1) understanding the internet, web, email, text chat, video conferencing, document sharing and forms, and security.

Some reasons related to the use of technology by counselors include (1) students or clients often cover the other problems that can harm their career directly (2) some individuals do not benefit from counseling with technology, this is due to the differences in learning styles (3) some research showed that the most effective intervention is the combination of technology and counselor support. Whereas, some types of computer utilization in counseling includes: (1) assessment - uniting the purpose of managing and interpreting the assessment instruments (2) counseling information system including some database and search strategies through ICT (3) counseling planning system- in addition to previously mentioned, also providing assessment and career planning process and storing the user record.

Therefore, before making any further stages related to the design of model and counseling program as a whole, the use and readiness of counselor in integrating technology should be examined in this study. This study aimed to provide an overview related to the use and readiness of the counselor in the integration of information and communication technology.

\section{METHOD}

Based on the survey results related to the development of continuous professionalism for counselor, the data results were then descriptively analyzed. Data collection was conducted from July to August 2017 after previously performing the instrument validation. The data collection results were presented in two major sections namely the part related to the description identity of the respondent and the description of the results of the questionnaire based on the statement or question in accordance with the indicators presented in the form of a percentage or qualitative description related to the respondent's answer.

The subjects of this study consisted of 156 counselors from Malang, Kupang, Ponorogo, Manado, and Palangkaraya. All of the respondents were counselors who later conducted further data through the distribution of semi-closed questionnaires. Data collection was conducted in July to August 2017. The results of data collection were presented in the form of a percentage or qualitative description related to the open answers of respondents that were then analyzed descriptively.

The data of the respondents on age classification are presented in the interval data from the age under twenty-five to the age of respondent. The age classification is presented in Table 1.

Based on the data presented in Table 1 , it is known that there were 11 respondents or $7.1 \%$ who were $\leq 25$ years old. As for the classification of age 26-30 years, there were 22 respondents $(14.1 \%)$. There were 19 respondents $(12.1 \%)$ who occupied the age classification of 31-35 years. In the age range of 36-40 years old was filled by 17 respondents (10.9\%). The classification age of 41-45 years old had the same number of respondents with age $\leq 25$ years old that was equal to 11 respondents. There were 76 respondents $(48.7 \%)$ who occupied the classification of age $\geq 46$ years old and this classification became the majority of counselor's age. Based on the description it is known that the age distribution of respondents is almost evenly distributed.

\section{RESULT AND DISCUSSION}

\section{A. Mostly Used-BK Media in Providing Counseling Services}

The majority of respondents stated that PowerPoint became the mostly used-BK medium with a response amounted to 102 $(67.1 \%)$. The second place was occupied by the use of video media in delivery service. As for the answers that at least have the same answer in respondents namely the use of cards, BK devices, career books, and LINE. The data are presented in Fig. 1.

TABLE I. DISTRIBUTION OF RESPONDENTS BY AGE

\begin{tabular}{|l|l|l|l|}
\hline \multicolumn{1}{|c|}{ No } & \multicolumn{1}{c|}{ Age } & Frequency & Percentage \\
\hline 1 & $\leq 25$ & 11 & $7.1 \%$ \\
\hline 2 & $26-30$ & 22 & $14.1 \%$ \\
\hline 3 & $31-35$ & 19 & $12.2 \%$ \\
\hline 4 & $36-40$ & 17 & $10.9 \%$ \\
\hline 5 & $41-45$ & 11 & $7.1 \%$ \\
\hline 6 & $\geq 46$ & 76 & $48.7 \%$ \\
\hline Amount & & 156 & $100 \%$ \\
\hline
\end{tabular}

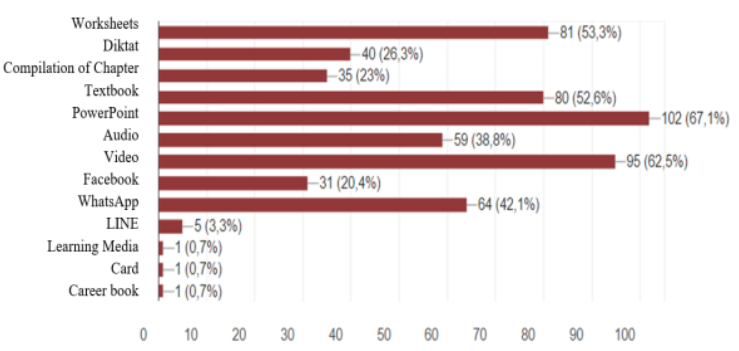

Fig. 1. BK Media Used for Service

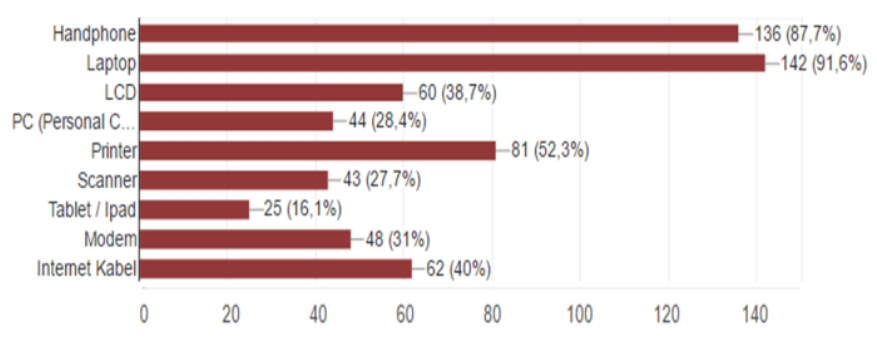

Fig. 2. Facilities owned for access to the learning resources 


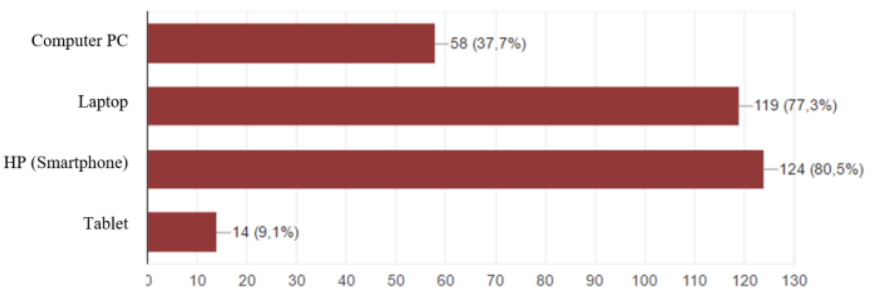

Fig. 3. Devices that are More Frequently Used When Accessing the Internet

\section{B. Facilities and Internet Access}

Fig. 2. Presents the following data related to the private facilities owned by accessing to the learning resources. The majority of respondents stated that the greatest access were laptop (142 responses) and mobile (136 responses) whereas the Tablet or iPad become the fewest facilities owned and used as a learning resource access.

The device that is more frequently used for the internet access namely HP (smartphones) that was selected by 124 respondents $(80.5 \%)$ as illustrated in Fig. 3. The fewest data was the use of tablet to access the Internet because it was only chosen by 14 respondents.

The further data are related to the most frequently performed activities when using the internet Table 2. Based on Fig. 4, there are the image data that are not too far from the items provided by opening social media, email, messaging (chat), reading news, and searching for learning materials. The fewest response was found in the data related to journal searching stated by 60 respondents $(38,7 \%)$.

The intensity of access to information becomes the last question item in the facility and internet section presented in Fig. 4. The intensity of categories are divided into five categories namely the use of under 2 hours per day, 2 to 3 hours per day, 3-5 hours per day, $4-5$ hours per day, and over 5 hours per day. Based on Fig. 4, 47.3\% of respondents stated that the internet usage was active for $2-3$ hours per day. The use of 4-5 hours per day, and over 5 hours per day became the fewest options selected by the respondents.

\section{BK Online Services}

The use of BK online services is presented in Fig. 5. The data show that some respondents stated that they have and some of them stated that they never have a small difference amounted to $0.8 \%$.

TABLE II. THE MOST FREQUENTLY PERFORMED ACTIVITIES WHEN USING THE INTERNET

\begin{tabular}{|l|l|l|}
\hline No & \multicolumn{1}{|c|}{ BK Online Services } & \multicolumn{1}{c|}{ n } \\
\hline 1 & Opening social media & $109(70.3 \%)$ \\
\hline 2 & Opening the e-mail & $94(60.6 \%)$ \\
\hline 3 & Sending a message (chatting) & $100(64.5 \%)$ \\
\hline 4 & Reading news & $116(74.8 \%)$ \\
\hline 5 & Looking materials for learning & $126(81.3 \%)$ \\
\hline 6 & Looking for a journal & $60(38,7 \%)$ \\
\hline
\end{tabular}

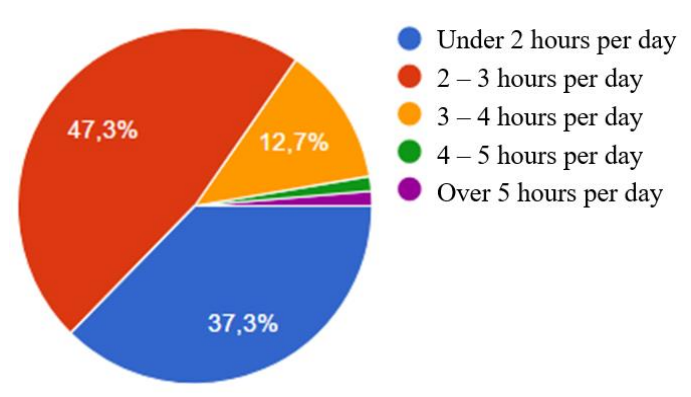

Fig. 4. The Intensity of information access

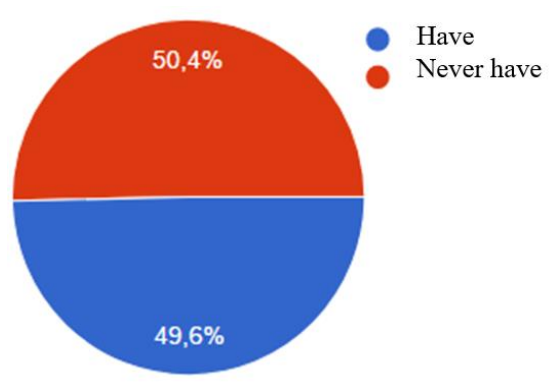

Fig. 5. The Use of BK Online service

TABLE III. The ACCOUNTABLE BK ONLINE SERVICES

\begin{tabular}{|l|l|l|}
\hline No & Counseling Services & \multicolumn{1}{|c|}{ n } \\
\hline 1 & WEB (cyber counseling) & $27(50 \%)$ \\
\hline 2 & Moodle & $7(13 \%)$ \\
\hline 3 & Edmodo & $13(24.1 \%)$ \\
\hline 4 & Google Classroom & $15(27.8 \%)$ \\
\hline 5 & WA, LINE, BBM, FB & $13(24.1 \%)$ \\
\hline
\end{tabular}

Furthermore, associated with the known BK online service, 27 respondents stated that the service was via the WEB (cybercounseling). Furthermore, 15 respondents (27.8\%) stated that BK online service used Google Classroom. The data can be seen in Table 3.

In this study, the counselor's usage of ITC was tried to be revealed. According to this result, most participants used PowerPoint in giving services to their students. The most popular presentation software both in educational and business contexts is PowerPoint [10]. Specifically, in an educational context, Warner [11] gave a recommendation that using PowerPoint is not to enhance the lecture presentation but to enhance the learner. Hence, teacher or counselor must use PowerPoint interactively, not just deliver the learning contents.

The next discussion is about the facilities used when accessing the internet. Mostly, the participants chose smartphone and laptop to access the internet. Some advantages that can be gained by using smartphones in an educational context are exam preparation, language study, note taking, and instant messaging [12]. Based on the literature, it is well known that one of the reasons related to the use of technology by counselors is the counseling session can be done directly through their gadgets in anywhere and anytime. Furthermore, Bastemur \& Bastemur [8] revealed that counselors feel positive sides of using online counseling although most of the 
counselors think that they do not have enough knowledge about online counseling.

Concerning survey results related to the activities in using the internet, most participants used the internet to prepare the learning resources especially in relation to the academic material. However, searching for journals gained the lowest percentage when counselors access the internet. This tendency can also be seen in the university students that use journal databases such as ERIC or Dogpile is in low category [13]. Additionally, the findings also revealed that in this research, participants used the internet to read the news and to communicate with others through social media applications, such as WA or Facebook.

Besides the activities, the duration of using it became one of the main components related to the usage of internet by a counselor. The results showed that the participants mostly spent 2-3 hours each day. Surprisingly, BCG survey [14] showed that Indonesia spent the online time in 0,89 hours per day and it prospectively increased, while China, US, and Japan spent more than 2 hours per day.

The participants were also asked about the usage of online counseling or cyber counseling. Half of the participants said that they did not use cyber counseling in serving their students. Furthermore, the participants who said "yes" then were asked about the software or application used in doing cyber counseling of which half used WEB, while Google Classroom, Edmodo, and Social Media Apps (WA, LINE) almost shared the same percentage. Moodle, one of the MOOC (Massive Open Online Class) programs had the lowest number of responses from the participants. In Henry's study [15], it was stated that age played a significant role in implementing technology successfully.

Following that finding, Van Der Kaay and Young [16] explored the different technology usage of a faculty member that the older member was not likely the younger member when integrating ITC in their learning. Based on the participant's age distributions, almost half of the participants were categorized as an older group with the age range of more than 46 years old. According to [9], the most principal key to provide a better experience in online counseling is the familiarity with the technology and the calm in facing technical problems. Based on the previous study, Mallen [17] stated that online counselor should receive training of communication and experience of new technologies, such as interpreting text messages.

As the ITCs evolved in the counseling session, counsellor must have an understanding the ITCs, especially the basic component of online counseling which consisted of understanding of component of online communication such as communication through email, social media application etc, understanding of its policy, and understanding of ethical considerations in doing online counseling, and security awareness. In addition, this prospective view of using online counseling can provide better opportunities for a student in accessing the effective counseling; it may be the better solutions of the future needs in counseling.

\section{CONCLUSION}

In general, Indonesian Counselor Competence Standards have been mandated to all counselors to master the computer technology and the internet for the benefit of providing guidance and counseling services at school. Furthermore, some essential components of professional counselor are the usage and the integration of information and technology to their works. Every counselor should be aware of the needs and the importance of using and integrating ITC. Many counselors reported having access to technologies that are rarely used for counseling and many of the programs offered are open access and online-based.

These findings directly contribute to make the effective and better services for students in elevating the counselor's professionalism. Thereby, it is necessary to conduct a training to increase the self-efficacy of the counselor in using cyber counseling. In that case, a proper development research is also needed to provide a suitable content or model to increase the counselor's professionalism related to the counselor's ITCs competency of. Future research related to this field is also recommended to enhance and promote not only the counselor's professionalism but also the counselor's continuing professional development program.

\section{REFERENCES}

[1] F. J. Hanna, F. Bemak, and R. C. Y. Chung, "Toward a new paradigm for multicultural counseling," J. Couns. Dev., vol. 77, no. 2, pp. 125134, 1999.

[2] ABKIN, "Penataan Pendidikan Profesional Konselor," Jakarta, 2007.

[3] J. Brown and R. Pets, Being a counselor. Monterey: Brooks/Cole, 1983.

[4] R. T. Joni, "Penataan Pendidikan Profesional Konselor. Profesional Dosen, Pra- jabatan," 2008, pp. 5-7.

[5] R. Jones, Basic Counseling Skills: A Helper's Manual. London: SAGE Publications, Inc, 2003.

[6] R. Jones, Introduction to counseling skill. Texts \& Activities. London: SAGE Publications, Inc, 2005.

[7] R. Jones, Practical counseling and helping skills. London: SAGE Publications, Inc, 2005

[8] S. Bastemur and E. Bastemur, "Technology based counseling: Perspectives of Turkish Counselors," Procedia-Social Behav. Sci., vol. 176, no. 20 Feb 2015, pp. 431-438, 2015.

[9] R. Kraus, G. Stricker, and C. Speyer, Online Counseling: A Handbook for Mental Health Professionals. London: Academic Press, 2011.

[10] R. J. Craig and J. H. Amernic, "PowerPoint presentation technology and the dynamics of teaching," Innov. High. Educ., vol. 31, no. 3, pp. 147-160, 2006.

[11] T. Warner, "Enhancing Student Engagement and Active Learning through Just-in-Time Teaching and the Use of PowerPoint," Int. J. Teach. Learn. High. Educ., vol. 7, no. 1, pp. 154-163, 2015.

[12] B. Patten, I. A. Sánchez, and B. Tangney, "Designing collaborative, constructionist and contextual applications for handheld devices," Comput. Educ., vol. 43, no. 6, pp. 294-308, 2006.

[13] B. Muniandy, "Academic use of internet among undergraduate students: a preliminary case study in a Malaysian university," Int. J. Cyber Soc. Educ., vol. 3, no. 2, pp. 171-178, 2010.

[14] BCG, “The Internet's New Billion Digital Consumers in Brazil, Russia, India, China, and Indonesia.," www.bcg.com, 2010. [Online]. Available: https://www.bcg.com/documents/file58645.pdf.

[15] A. M. Henry, The relationship of age, gender, and personality style with the level of technology implementation at the university level. Minneapolis: Walden University, 2008. 
[16] C. D. Van der Kaay and W. Young, "Age - related differences in technology usage among community college faculty," Community Coll. J. Res. Pract., vol. 36, no. 8, pp. 570-579, 2012.

[17] M. J. Mallen, D. L. Vogel, and A. B. Rochlen, "The practical aspects of online counseling: Ethics, training, technology, and competency," Couns. Psychol., vol. 33, no. 6, pp. 776-818, 2005. 